\title{
Factors associated with ovarian structures and intrauterine fluid in the postpartum period in dairy cows
}

\author{
I. López-Helguera, ${ }^{*} \dagger$ M. G. Colazo, $\dagger^{1}$ I. Garcia-Ispierto, ${ }^{*}$ and F. López-Gatius ${ }^{*}$ \\ *Department of Animal Production, Agotecnio Centre, University of Lleida, Lleida, Spain 25198 \\ †Livestock Research Branch, Alberta Agriculture and Forestry, Edmonton, AB, Canada T6H 5T6
}

\begin{abstract}
The objective was to examine risk factors for the interval to resumption of ovarian cyclicity (ROC), multiple ovulations (MCL), ovarian follicular cysts (OC), and presence of intrauterine fluid (IUF) at 22 to 28 [visit (V) 1] and 36 to 42 (V2) days in milk (DIM) in dairy cows. The study was conducted retrospectively by evaluating records from 1,155 Holstein cows from 3 herds. Ovaries and uteri were examined at V1 and V2 by transrectal ultrasonography to determine ovarian structures and IUF. Based on the odds ratio, multiparous cows were more likely to have ROC at V1 by a factor of 1.79 compared with primiparous cows. The likelihood of ROC at V1 was lower in cows with higher milk production, in cows with retained fetal membranes (RFM) or cows with IUF at V1 by factors of 0.98 (for each $\mathrm{kg}$ of milk increased), 0.52, and 0.61, respectively. Based on the odds ratio, cows diagnosed with IUF at V2 were 2.85 times more likely to have attained ROC at V2. Multiparous cows and cows that delivered twins were 2.73 and 2.16 times, respectively, more likely to have MCL at V1, whereas cows with RFM were 0.38 times less likely to have MCL at V1. The likelihood of MCL at V2 was higher in cows with MCL and OC at V1 by factors of 2.67 and 1.91, respectively. Multiparous cows were 8.51 times more likely to have OC at V1 than primiparous cows. Higher producing cows were more likely to have OC at V2 by a factor of 1.04 compared with lower producing cows. Parity, stillbirth, RFM, and ROC at V1 were all identified as risk factors for IUF at V1. Cows with RFM and delivering twins were more likely to be diagnosed with IUF at V2 by a factor of 3.43 and 4.07, respectively. In summary, parity, twinning, RFM, metritis, IUF, and milk production were all associated with altered ovarian structures, and the presence of IUF was related to parity, twinning, RFM, and ROC in postpartum dairy cows.
\end{abstract}

Received November 10, 2015.

Accepted January 20, 2016.

${ }^{1}$ Corresponding author: marcos.colazo@gov.ab.ca
Key words: puerperium, double ovulation, cyclicity

\section{INTRODUCTION}

In dairy cows, the early postpartum period has been recognized as a critical time that dramatically influences subsequent reproductive performance (LeBlanc, 2008). Cows must attain adequate uterine involution and return to ovarian cyclicity before the end of the voluntary waiting period to become pregnant in a timely manner (Morrow et al., 1969; Shrestha et al., 2004; LeBlanc, 2008). However, this is a very dynamic and complex process, in which the uterus and ovaries are intimately associated. In this regard, endotoxins from postpartum uterine infections can disturb ovarian folliculogenesis and prolong the anovulatory period (Sheldon et al., 2002), whereas imbalanced ovarian endocrine function can impair local immune responses required for uterine recovery (Lewis, 2004). In addition, the intrauterine fluid (IUF) has been associated with impaired conception rate after first AI (Kasimanickam et al., 2004; Dourey et al., 2011; López-Helguera et al., 2012), and delayed resumption of ovarian cyclicity (ROC) have been shown to delay first insemination (Walsh et al., 2007) and negatively affect the fertility of the cow (Fourichon et al., 2000).

Usually, only one follicle within each follicular wave is selected to become dominant; however, codominance often occurs in lactating dairy cattle leading to double ovulation and increasing the risk of twin pregnancy (review in Wiltbank et al., 2000). Twin pregnancies are undesirable in dairy herds because they dramatically increase the risk of pregnancy loss during the first trimester of gestation (López-Gatius and GarciaIspierto, 2010; López-Gatius, 2012) and dystocia (Mee 1991), which has been associated with a decreased in the productive lifespan of cows (Andreu-Vázquez et al., 2012a). Occurrence of ovarian follicular cysts (OC), an alteration of follicular development, is also a common finding during early postpartum period in dairy cattle. Although OC have been reported to be one of the main causes of infertility in dairy cattle (Garverick, 1997; 
Yániz et al., 2004), the predisposing risk factors are still controversial. Although some factors such as retained fetal membranes (RFM) or metritis have been previously shown to affect the incidence of ROC (Opsomer et al., 2000; Vercouteren et al., 2015) and OC (LópezGatius et al., 2002), the effect of milk production on ovarian follicular dynamics remains debatable. Contradictory results have been reported regarding relationships between milk production and multiple ovulations (MCL; Fricke and Wiltbank, 1999; López-Gatius et al., 2005), ROC (Walsh et al., 2007; Dubuc et al., 2012), and OC (Nanda et al., 1989; López-Gatius et al., 2002; Tsousis et al., 2009).

According to Dubuc et al. (2012) and Vercouteren et al. (2015), cows that calved during summer months were more likely to have a shorter interval from calving to ROC compared with those that calved in winter months. However, several studies in our area (LópezGatius, 2003; López-Gatius et al., 2005, 2008; GarciaIspierto et al., 2007; Yániz et al., 2008) and elsewhere (López-Gatius, 2012; De Rensis et al., 2015) have suggested that cows calving in warmer months have an increased incidence of postpartum anestrus.

The objective of this retrospective study was to identify risk factors associated with ROC, MCL, OC, and IUF at 22 to 28 and 36 to 42 DIM in dairy cows from 3 well-managed commercial dairy herds.

\section{MATERIALS AND METHODS}

\section{Cattle and Herd Management}

This is a retrospective observational cohort study whose data were retrieved from a reproductive control program from October 2013 to September 2014 on 3 well-managed commercial dairy herds in north-eastern Spain by the University of Lleida. The mean number of lactating Holstein-Friesian cows during the study period were 1,850,780, and 190 for herds 1,2 , and 3, respectively. However, the data analyzed were derived from a total of 1,155 cows (330 primiparous and 825 multiparous). Briefly, herd management included the following common features: the use of pedometers for estrous activity, housing in free stalls with concrete slatted floors and cubicles, the use of fans and water sprinklers in the warm season, daily postpartum checks, the same reproductive health program, and confirmation of estrus at AI performed by veterinarians. The mean annual milk production for the herds over the study period was $11,340 \mathrm{~kg}$, with a mean annual culling rate of $31 \%$. The cows were grouped according to parity (primiparous vs. multiparous), milked 3 times daily, and fed TMR with diets consisting of cotton seed hulls, barley, corn, soybean meal, and bran, and roughage, primarily corn, barley or alfalfa silage, and alfalfa hay. Rations were formulated according to NRC recommendations (NRC, 2001). All cows had a dry period of approximately $45 \mathrm{~d}$ before the expected calving date. Dry cows were kept in a separate group (far-off group) and moved 7 to $25 \mathrm{~d}$ before the expected calving date to a close-up group depending on their BCS (Roche et al., 2000; López-Gatius et al., 2003) and if they were carrying twins (López-Gatius and Garcia-Ispierto, 2010). After parturition, a fresh group was established for closer health monitoring, and then, primiparous and multiparous lactating cows were transferred to 2 separate groups approximately 7 to $15 \mathrm{~d}$ postpartum.

\section{Reproductive and Health Management}

Cows were monitored daily during postpartum period. The following puerperal diseases were treated until resolved or until culling: signs of injury to the genital area (i.e., vaginal or recto-vulvar lacerations), RFM (retention of fetal membranes for more than 12 $\mathrm{h}$ after parturition), or puerperal metritis [diagnosed during the first or second week postpartum by fetid red-brown watery uterine discharge with or without pyrexia (Sheldon et al., 2006)].

The herds were maintained on a weekly reproductive health program. This involved examining the reproductive tract of each animal by transrectal ultrasonography with a $7.5-\mathrm{MHz}$ transducer (Easi Scan, BCF Technology Ltd., Livingston, UK) from 22 to 28 and 36 to 42 DIM to determine ovarian structures and the presence of IUF (López-Helguera et al., 2012). Ovaries were scanned in several planes by moving the transducer along the surface to determine follicular development and the presence and number of corpus lutea (CL). An OC was defined as a follicular structure $\geq 25 \mathrm{~mm}$ in diameter (external diameter including the wall) in either or both ovaries in the absence of a CL and uterine tone (Garverick, 1997; Colazo et al., 2015). Ultrasonography was also performed across the dorsal/lateral surface of each horn to determine the presence of IUF (LópezHelguera et al., 2012).

Because the incidence of RFM or puerperal metritis has been associated with subsequent pregnancy loss (López-Gatius et al., 1996), cows diagnosed with either disorder were treated with intrauterine oxytetracycline boluses (500 mg of Terramicina i.u.; Zoetis, Madrid, Spain) and ceftiofur (750 mg, $15 \mathrm{~mL}$ of Eficur s.c.; Hipra, Girona, Spain) daily for 3 to 5 d, respectively. Prostaglandin $\mathrm{F}_{2 \alpha}$ (25 mg of dinoprost i.m.; Enzaprost, CEVA Santé Animale, Libourne, France) was used to treat pyometra after confirming the presence of CL. The treatment for $\mathrm{OC}$ consisted of manual rupture per 
rectum and a single injection of $\mathrm{PGF}_{2 \alpha}(25 \mathrm{mg}$ of dinoprost i.m.; Enzaprost, CEVA Santé Animale) at the same time of rupture (Hanzen et al., 2008).

The voluntary waiting period was $50 \mathrm{~d}$, and thereafter, cows were artificially inseminated based on estrus detection by use of pedometers. Those cows not inseminated by 71 to 77 DIM were subjected to weekly estrous and ovulation synchronization programs that included specific treatments depending on their ovarian structures (López-Gatius et al., 2008).

\section{Statistical Analysis}

The following data were recorded for each animal: herd (H1, H2, and H3), date of calving, parity (primiparous vs. multiparous), twinning and occurrence of stillbirth at calving, RFM, metritis, milk production (mean of milk yield recorded 47, 48, and 49 DIM), size and number of ovarian follicles and CL, and presence of IUF on 22 to 28 DIM [visit (V) 1] and 36 to 42 DIM (V2). Parturition dates were used to determine the season of calving (spring: March 20-June 20; summer: June 21-September 22; autumn: September 23-December 20; winter: December 21-March 19).

Cows were categorized into 5 groups based on their ovarian structures at V1 and V2: presence of one CL (CL), 2 or more CL (MCL), OC (follicular structures $>20 \mathrm{~mm}$ ), follicles between 5 and $20 \mathrm{~mm}$ (FOL) in absence of CL, and inactive ovary (considered as absence of CL and follicular structures $<5 \mathrm{~mm}$ ). The variable ROC was defined as the presence of at least one CL at V1 or V2.

For statistical analyses, 8 logistic regression analyses using a binary distribution were performed. The dependent variables considered in these analyses were ROC, MCL, OC, and IUF at V1 and V2. Independent variables were season of parturition, parity, twinning, stillbirth, RFM, metritis, and milk production. For the dependent variables in V2, ROC, MCL, OC, and IUF at V1 were also added as independent variables.

Regression analyses were conducted according to the method of Hosmer and Lemeshow (Hosmer and Lemeshow, 1989) using the logistic procedure of the SPSS package, version 18.0 (SPSS, IBM, Chicago, IL). Basically, this method involves 5 steps as follows: preliminary screening of all variables for univariate associations; construction of a full model using all the variables found to be significant in the univariate analysis; stepwise removal of nonsignificant variables from the full model and comparison of the reduced model with the previous model for model fit and confounding; evaluation of plausible 2-way interactions among variables and assessment of model fit using Hosmer-Lemeshow statistics. Variables with univariate associations showing a $P<0.25$ were included in the initial model. Modeling was continued until all the main effects or interaction terms were significant according to the Wald statistic at $P<0.05$. Probabilities of $P<0.05$ were considered significant. Power analysis for the logistic regression was conducted using the $\mathrm{G}^{*}$ Power 3.1 (Faul et al., 2007). Using an $\alpha$ of 0.05 , a power of 0.80 , and a 2 -tailed test, the desired sample size was 69,171 , and 1,484 for variables with odd ratios of $2.5,1.7$, and 1.2 , respectively.

\section{RESULTS}

The mean $( \pm \mathrm{SD})$ lactation number was $2.5 \pm 1.5$ (range: 1-9 lactations). The daily milk production averaged over 47, 48 and 49 DIM was $52 \pm 12.2 \mathrm{~kg}$ (range: 24-104 kg). Of the total 1,155 cows, 1,109 (96\%) cows delivered singletons with $69(6.2 \%)$ stillbirths, 91 (8.2\%) RFM, and 160 (14.4\%) metritis. Forty-six (3.9\%) cows delivered twins with 18 (39.1\%), 13 (28.3\%), and 17 (37.0\%) stillbirths, RFM, and metritis, respectively. Two hundred seventy-one, 224, 278, and 382 calved in spring, summer, autumn, and winter, respectively.

The incidence of ovarian luteal and follicular structures on V1 and V2 is shown in Table 1. Five hundred twenty-seven $(45.6 \%)$ and $401(34.7 \%)$ cows were categorized as FOL at V1 and V2, respectively, and 525 $(45.5 \%)$ and $711(61.5 \%)$ cows had ROC at the times of V1 and V2, respectively. Of the 130 cows with MCL at V1, 93 were unilateral (71.5\%) and 37 bilateral (28.5\%), and 6 cows had 3 CL. During V2, 177 cows had MCL [109 were unilateral (61.6\%) and 68 bilateral (38.4\%)], 8 cows had 3 CL and 2 cows had 4 CL. Eighty-two $(7.1 \%)$ and $37(3.2 \%)$ cows had $\mathrm{OC}$ at V1 and V2, respectively, whereas 21 and 6 cows had inactive ovaries at V1 and V2, respectively. Only one cow had inactive ovaries on both visits.

The odds ratios of the variables included in the logistic regression model for factors affecting ROC are shown in Table 2. The likelihood of ROC at V1 was lower in herds 2 and 3 than in herd 1 (by a factor of 0.60 and 0.41 , respectively; $P<0.001$ ) and lower in cows with higher milk production (by a factor 0.98 for each $\mathrm{kg}$ of milk increased; $P=0.016)$. Cows with RFM and IUF at V1 were $0.52(P=0.005)$ and $0.61(P=$ $0.02)$ less likely to have ROC at V1 than cows without RFM and IUF. Multiparous cows were more likely to have ROC at $\mathrm{V} 2$ by a factor of 1.36 compared with primiparous cows $(P=0.02)$. The likelihood of ROC at V2 was 0.68 times lower in cows that had shown signs of metritis compared with those that did not $(P=0.027)$. Cows with ROC at V1 were 2.85 times more likely to have ROC at V2 compared with cows without ROC at V1 $(P<0.001)$. The likelihood of ROC at V2 was 2.91 
Table 1. Ovarian structures recorded on d 22 to 28 (V1) and 36 to 42 (V2) postpartum in 1,155 lactating dairy cows

\begin{tabular}{|c|c|c|c|c|c|c|c|c|}
\hline Ovarian structure $^{1}$ & \multicolumn{4}{|c|}{ d $22-28$} & \multicolumn{4}{|c|}{ d $36-42$} \\
\hline FOL, no. $(\%)$ & $527(45.6)$ & $180(40.5)$ & $297(47.6)$ & $50(57.5)$ & $401(34.7)$ & $151(34)$ & $213(34.1)$ & $37(42.5)$ \\
\hline MCL, no. $(\%)$ & $130(11.3)$ & $53(11.9)$ & $73(11.7)$ & $4(4.6)$ & $177(15.3)$ & $58(13.1)$ & $106(17.0)$ & $13(14.9)$ \\
\hline OC, no. $(\%)$ & $82(7.1)$ & $28(6.3)$ & $50(8.0)$ & $4(4.6)$ & $37(3.2)$ & $2(0.5)$ & $27(4.3)$ & $8(9.2)$ \\
\hline Inactive, no. (\%) & $21(1.8)$ & $9(2.0)$ & $10(1.6)$ & $2(2.3)$ & $6(0.5)$ & $0(0)$ & $6(1.0)$ & $0(0)$ \\
\hline
\end{tabular}

${ }^{1} \mathrm{FOL}=$ presence of at least 1 follicle between 5 and $20 \mathrm{~mm}$ in diameter in absence of corpus luteum (CL); CL = presence of 1 single CL; MCL $=$ presence of 2 or more CL; OC $=$ ovarian follicular cyst, follicular structures $>20 \mathrm{~mm}$; inactive $=$ absence of CL and follicular structures $>5 \mathrm{~mm}$.

times higher in cows with IUF at V2 compared with cows without signs of IUF at V2 $(P=0.022)$.

The odds ratios of the variables affecting MCL are shown in Table 3. Based on the odds ratio, the likelihood of MCL at V1 was lower by a factor of 0.38 in cows with RFM $(P=0.03)$. Multiparous cows were more likely to have MCL at V1 (by a factor of 2.73; $P<0.001)$ than primiparous cows. The likelihood of MCL at V1 was higher in cows calving twins (by a factor of 2.16; $P=0.051$ ) than cows calving singletons. Multiparous cows and those with IUF at V2 were more likely to have MCL at V2 (by factors of 3.11 and 3.03; $P<0.001$ and $P=0.006$, respectively) compared with primiparous cows and those without IUF. The likelihood of MCL at V2 was higher in cows with MCL and $\mathrm{OC}$ at $\mathrm{V} 1$ compared with remaining animals (by factors of 2.67 and $1.91 ; P<0.001$ and $P=0.01$, respectively).

Multiparous cows were 8.51 times more likely to have OC at V1 than primiparous cows $(P<0.001)$ and the likelihood of OC at V2 was higher in herds 2 and 3 than in herd 1 (by factors of 16.09 and 44.30, respectively; $P<0.001)$. Cows with higher milk production were more likely to have $\mathrm{OC}$ at $\mathrm{V} 2(\mathrm{OR}=1.04 ; P=0.027$; Table 4).

One hundred sixteen and 33 cows had IUF at V1 and V2, respectively. Parity, stillbirth, RFM, and ROC at V1 influenced incidence of IUF at V1. Based on the odds ratio, the likelihood of IUF at V1 was higher in multiparous cows and in cows with RFM compared with primiparous cows and those without RFM (by factors of 2.75 and 3.59 , respectively; $P<0.001$ ). Cows with stillbirth were 2.23 times more likely to have IUF at V1 than remaining cows $(P=0.012)$. Cows with ROC at V1 were 0.61 times less likely to have IUF at $\mathrm{V} 1$ than the remaining cows $(P=0.018)$. Of the 33 cows diagnosed with IUF at V2, $10(30.3 \%)$ had been diagnosed previously with IUF at V1, whereas the remaining $23(69.7 \%)$ cows were diagnosed with IUF for

Table 2. Odds ratios of the independent variables included in the final logistic regression model for factors affecting resumption of ovarian cyclicity $(\mathrm{ROC})$ in lactating dairy cows $(\mathrm{n}=1,155)^{1}$

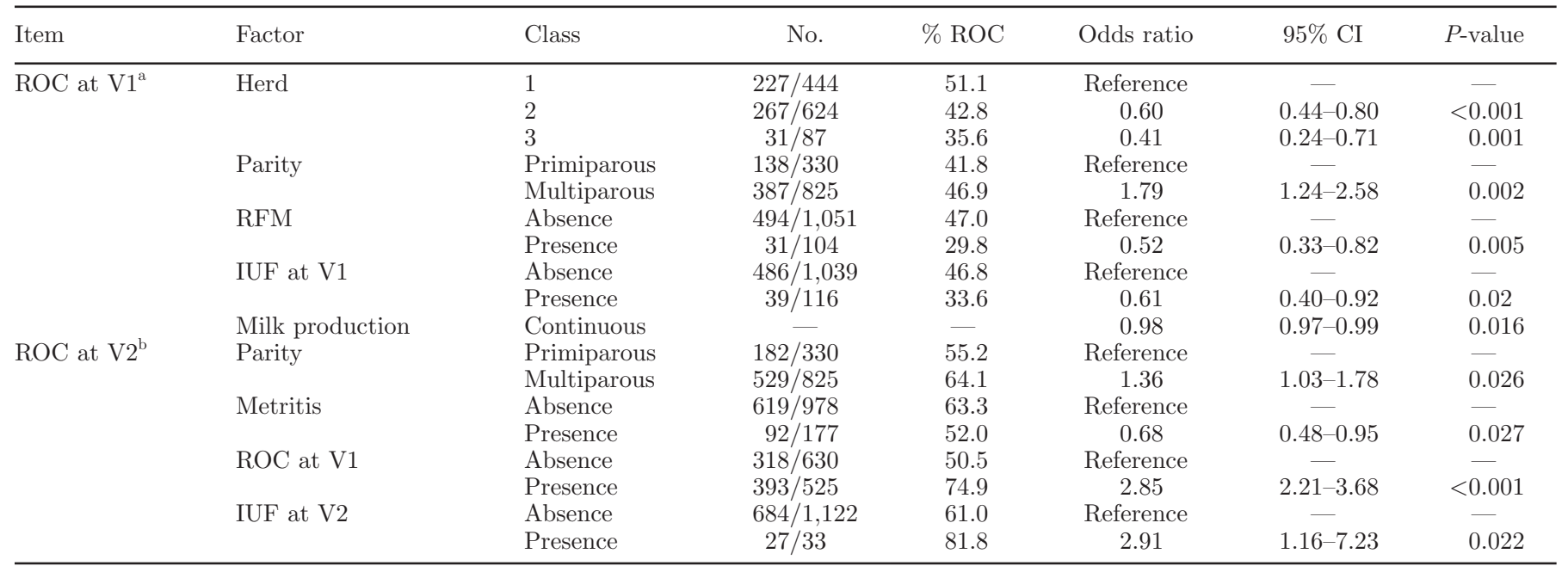

${ }^{\mathrm{a}} \mathrm{R}$ Nagelkerke $=0.109, P=0.019 ;{ }^{\mathrm{b}} \mathrm{R}$ Nagelkerke $=0.076, P=0.010$.

${ }^{1}$ Visit (V) 1 = 22 to 28 DIM; V2 = 36 to 42 DIM; ROC = resumption of ovarian cyclicity, presence of at least 1 corpus luteum; RFM = retained fetal membranes $>12 \mathrm{~h}$ after calving; IUF = intrauterine fluid (cows with intrauterine fluid detected by ultrasonography). 
Table 3. Odds ratios of the independent variables included in the final logistic regression model for factors affecting multiple ovulation (MCL) in lactating dairy cows $(\mathrm{n}=1,155)^{1}$

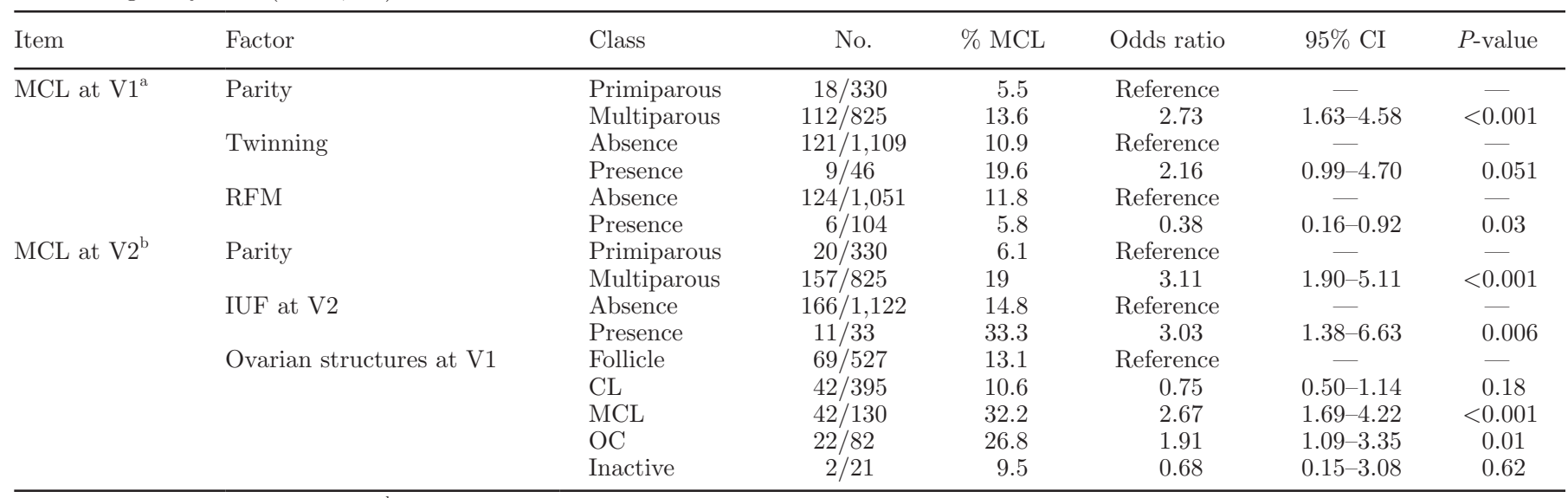

${ }^{\mathrm{a}} \mathrm{R}$ Nagelkerke $=0.068, P=0.07 ;{ }^{\mathrm{b}} \mathrm{R}$ Nagelkerke $=0.106, P=0.009$.

${ }^{1}$ Visit (V) $1=22$ to 28 DIM; V2 = 36 to 42 DIM; MCL = multiple ovulation defined as presence or 2 or more corpora lutea (CL); RFM = retained fetal membranes $12 \mathrm{~h}$ after calving; IUF = intrauterine fluid (cows with intrauterine fluid detected by ultrasonography); OC $=$ ovarian cyst (follicular structures $>20 \mathrm{~mm}$ ); inactive $=$ absence of CL and follicles $>5 \mathrm{~mm}$.

the first time $(P<0.001)$. Cows with RFM and calving twins were more likely to have IUF at V2 by factors of $3.43(P=0.005)$ and $4.07(P=0.008)$, respectively. The likelihood of IUF at V2 was higher in animals with $\mathrm{ROC}$ at $\mathrm{V} 2(\mathrm{OR}=3.43 ; P=0.008)$. Metritis was an intervening variable in the RFM-IUF relationship because controlling for metritis changed the odd ratio of the variables included in the final regression model. Results of the discriminant analysis are shown in Table 5 .

\section{DISCUSSION}

This retrospective study was conducted to identify risk factors for ROC, MCL, OC, and the presence of IUF at 2 times during postpartum period in 1,155 dairy cows from 3 herds located in Northern Spain.

The overall ROC was 45.5 and $61.5 \%$ at 22 to 28 and 36 to 42 DIM, respectively. Although previous studies have reported similar results (Opsomer et al., 2000; Vercouteren et al., 2015), others found a lower percentage of cyclic cows $(28$ and $31.4 \%$ at the third and fourth week, respectively) in the early postpartum period (Senosy et al., 2009; Dubuc et al., 2012). The lower percentage of cyclic cows reported in the latter studies were, perhaps, due to differences in determining cyclicity. Ultrasonography was used in the current study, whereas circulating concentrations of progesterone were used to determine the presence of a functional CL in previous study (Dubuc et al., 2012). Although circulating progesterone is the gold standard test for determining CL function, a single point measurement might underestimate the incidence of ROC because progesterone concentrations are low during the first days of the estrous cycle and its decline begins before luteal tissue area regression (Kastelic et al., 1990; Ribadu et al., 1994). Another factor that could explain the differences in ROC between our study and earlier reports could be nutrition management among herds. The negative energy balance (NEB) during the transition period has been reported to delay ROC (Butler et al., 1981; Roche et al., 2000) by inhibiting GnRH release (Schillo, 1992),

Table 4. Odds ratios of the independent variables included in the final logistic regression model for factors affecting ovarian cysts (OC) in lactating dairy cows $(\mathrm{n}=1,155)^{1}$

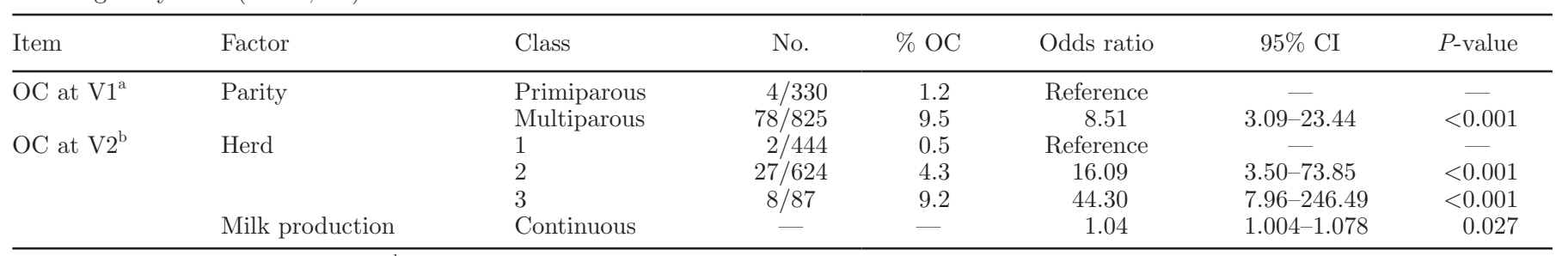

${ }^{\mathrm{a}} \mathrm{R}$ Nagelkerke $=0.069, P<0.001 ;{ }^{\mathrm{b}} \mathrm{R}$ Nagelkerke $=0.107, P=0.026$.

${ }^{1}$ Visit (V) $1=22$ to 28 DIM; V2 = 36 to 42 DIM; OC = ovarian cyst (follicular structures $>20 \mathrm{~mm}$ ). 
Table 5. Odds ratios of the independent variables included in the final logistic regression model for factors affecting intrauterine fluid (IUF) in lactating dairy cows $(\mathrm{n}=1,155)^{1}$

\begin{tabular}{|c|c|c|c|c|c|c|c|}
\hline Item & Factor & Class & No. & $\%$ IUF & Odds ratio & $95 \%$ CI & $P$-value \\
\hline \multirow{4}{*}{ IUF at $V 1^{a}$} & Parity & Multiparous & $99 / 825$ & 12.0 & 2.75 & $1.59-4.76$ & $<0.001$ \\
\hline & \multirow[t]{2}{*}{ RFM } & Absence & $87 / 1,051$ & 8.3 & Reference & - & - \\
\hline & & Presence & $29 / 104$ & 27.9 & 3.59 & $2.18-5.90$ & $<0.001$ \\
\hline & $\mathrm{ROC}$ at $\mathrm{V} 1$ & Absence & $77 / 630$ & 12.2 & Reference & - & - \\
\hline \multirow{5}{*}{ IUF at $V 2^{b}$} & Twinning & Presence & $5 / 46$ & 10.9 & 4.07 & $1.43-11.54$ & 0.008 \\
\hline & \multirow[t]{2}{*}{ RFM } & Absence & $25 / 1,051$ & 2.4 & Reference & - & - \\
\hline & & Presence & 8/104 & 7.7 & 3.43 & $1.45-8.10$ & 0.005 \\
\hline & \multirow[t]{2}{*}{$\mathrm{ROC}$ at $\mathrm{V} 2$} & Absence & $6 / 444$ & 1.4 & Reference & - & - \\
\hline & & Presence & $27 / 711$ & 3.8 & 3.43 & $1.37-8.58$ & 0.008 \\
\hline
\end{tabular}

${ }^{\mathrm{a}} \mathrm{R}$ Nagelkerke $=0.109, P=0.019 ;{ }^{\mathrm{b}} \mathrm{R}$ Nagelkerke $=0.076, P=0.010$.

${ }^{1}$ Visit (V) $1=22$ to 28 DIM; V2 = 36 to 42 DIM; IUF = intrauterine fluid (cows with intrauterine fluid detected by ultrasonography); RFM = retained fetal membranes $>12 \mathrm{~h}$ after calving; ROC $=$ resumption of ovarian cyclicity, presence of at least 1 corpus luteum.

decreasing plasma LH concentrations, and reducing the number of antral follicles and the estradiol produced by the dominant follicle (Lucy et al., 1992). Although NEB may have negatively affected ROC in the current study, the multifactorial statistical model used here did not include energy balance as an independent variable.

Metritis, RFM, and parity were identified as significant risk factors for ROC in the present study. Those cows with RFM and metritis were less likely to be cyclic at V1 and V2 in the present study, which is in agreement with previous studies (El-Din Zain et al., 1995; Vercouteren et al., 2015). Bacterial contamination of the uterus affects dominant follicle selection by affecting LH secretion (Sheldon et al., 2002) and, hence, could delay ROC in postpartum dairy cows. Parity was also identified as a significant risk factor for ROC. Multiparous cows were more likely to have ROC at $\mathrm{V} 1$ by a factor of 1.79 compared with primiparous cows. Similarly, multiparous cows were more likely to attain early ROC in the study by Tanaka et al. (2008). Primiparous cows are more likely to be in NEB due to the requirements for growth as well as lactation, delaying ROC.

Parity, twinning, and OC at V1 (22-28 DIM) were significant risk factors of MCL, whereas no effect was observed for milk production on MCL. Previous studies have shown that double ovulations at more advanced stages of lactation were affected by parity and twinning (Fricke and Wiltbank, 1999; López-Gatius et al., 2005). Moreover, it has been suggested that double ovulation and twinning rates increase with parity (Kinsel et al., 1998; López-Gatius et al., 2005). However, the prevalence of MCL has been related to different management factors (Cady and Van Vleck, 1978; López-Gatius et al., 2005; Dyck et al., 2011), and the heritability of
MCL has been documented (Van Vleck et al., 1991). We found that MCL at V2 (36-42 DIM) was also related to $\mathrm{OC}$ on preceding examination (V1), which is in agreement to previous studies (Labhsetwar et al., 1963; Kinsel et al., 1998; Andreu-Vázquez et al., 2012b). The etiology of OC might involve an endocrine imbalance of the hypothalamo-hypophysial axis (reviewed in Garverick, 1997 and Hanzen et al., 2007). Therefore, it is plausible that any endocrine alteration related to the OC condition, in particular GnRH or LH synthesis and release (or both), could alter follicular selection and result in enhanced double ovulation.

Interestingly, no effect of milk production was observed on MCL in the present study, reinforcing the previous findings where no association was found between milk production and the incidence of twin pregnancies (Andreu-Vázquez et al., 2012b). However, we should be cautious in interpreting this outcome as the low incidence of MCL might have resulted in a lack of statistical power when analyzing milk production as a continuous variable.

Previous observational studies of the effect of milk production on double ovulations in dairy cows have yielded controversial results. In this regard, milk production was positively correlated with the incidence of double ovulations (Fricke and Wiltbank, 1999; Lopez et al., 2005), whereas López-Gatius et al. (2005) observed that higher producing cows had a lower probability of double ovulations. It is important to note that these latter studies involved only cows subjected to timed AI programs or inseminated after estrus during late postpartum (Fricke and Wiltbank, 1999; López-Gatius et al., 2005). In the current study, the effect of milk production on MCL was examined in cows that had their first or second spontaneous ovulation shortly after 
calving. Our findings are also in agreement with those by Lopez et al. (2005); these authors observed no effect of level of milk yield on first postpartum ovulation. Thus, it is plausible that the effect of milk production on MCL after first postpartum ovulation might be related to an increased metabolism of the steroid hormones (in particular progesterone), which would affect LH secretion (Wiltbank et al., 2006). Furthermore, the differences in the timing of milk production data collection between studies $[2 \mathrm{~d}$ before AI (Fricke and Wiltbank, 1999), day of AI (López-Gatius et al., 2005), average of $14 \mathrm{~d}$ before estrus (Lopez et al., 2005), or 7 to $9 \mathrm{~d}$ after estimated ovulation (present study)] would also explain the controversial results reported in the literature about milk production and double ovulations in lactating dairy cows.

Milk production was determined to be a significant risk factor for $\mathrm{OC}$ and ROC. Although the overall prevalence of $\mathrm{OC}$ was similar to that published by López-Gatius et al. (2002), it was quite variable among herds (0.5-9.2\% at $36-42$ DIM). As reported previously (Johnson et al., 1966; López-Gatius et al., 2002), the presence of $\mathrm{OC}$ was associated with higher milk production. As discussed above, it has been suggested that $\mathrm{OC}$ is the result of an endocrine imbalance involving the hypothalamo-hypophysial axis (review in Garverick, 1997 and Hanzen et al., 2007). Considering that high milk production increases steroid hormone metabolism in the liver (Wiltbank et al., 2006), increased metabolism during peak lactation in high-producing animals would result in decreased peripheral estradiol and progesterone concentrations, altered circulating LH and FSH concentrations, and the development of persistence dominant follicles, which might lead to OC and delayed ROC.

Several approaches have been used to diagnose uterine inflammation to identify cows that may have subsequent impaired reproductive performance (review in de Boer et al., 2014). Recently, our group (López-Helguera et al., 2012) found that cows with IUF on 15 to 21 DIM had lower odds of becoming pregnant to the first insemination at 70 DIM compared with cows without IUF. These results were in agreement with previous studies that also evaluated the presence of IUF later in the postpartum period as an indicator for uterine inflammation (Kasimanickam et al., 2004; Barlund et al., 2008). Although the latter and our findings were not validated with uterine biopsy (i.e., gold standard test for diagnosing endometritis), all studies using the presence of IUF were useful to identify animals with lower pregnancy rate and then probably with postpartum uterine inflammation. Therefore, the risk factors associated with the presence of IUF were examined in the present study.
Resumption of ovarian cyclicity, stillbirth, twinning, RFM, and parity were identified as significant risk factors of IUF. In our study, acyclic cows were 1.64 times more likely to have IUF at V1 than cyclic cows, whereas cyclic cows at V2 were 3.43 times more likely to have IUF compared with acyclic cows. Whether a delay in ROC would diminish the incidence of IUF or if IUF disrupts ovarian activity cannot be elucidated from our data. Only $30 \%$ of cows with IUF at V2 were diagnosed with IUF at V1, which would suggest a different etiology for the presence of IUF at 22 to 28 versus 36 to 42 DIM. Previous studies have indicated that polymorphonuclear neutrophil function begins to decline by 3 to 5 wk before parturition, reaching a nadir between calving and $1 \mathrm{wk}$ postpartum, and then slowly returning to prepartum levels by 2 to 4 wk postpartum (Detilleux et al., 1995; Hammon et al., 2006). As discussed earlier, cows in a less severe NEB resume cyclicity sooner in the postpartum period, which affects the endocrine environment. Steroid hormones such estradiol or progesterone play immune-modulating roles that could affect the clearance or maintenance of uterine infections, respectively (Lewis, 2004). In this regard, circulating progesterone downregulates endometrial eicosanoids and leukotriene production, and reduces lymphocyte proliferation, increasing the chance for uterine infection (review by Lewis, 2004 and Singh et al., 2008). These physiological events would support the hypothesis that a complex interaction between ROC and presence of IUF would occur during puerperium. In this regard, stillbirth, twinning, RFM, and parity were all detected as significant risk factors for IUF. Peripartum disorders such as RFM, stillbirths, and twinning increase as number of lactations increases (Chassagne et al., 1998; Kinsel et al., 1998), and these disorders may contribute to uterine contamination (Gröhn and Rajala-Schultz, 2000; LeBlanc, 2008).

No effect of season of calving on ROC, OC, or IUF was observed. However, these findings should not be overinterpreted because only a limited number of animals within each variable were evaluated among the 4 seasons. Although heat stress has been described as an important factor that negatively affects steroidogenesis (Roth et al., 2001), folliculogenesis (Wolfenson et al., 1995), and fertility (Garcia-Ispierto et al., 2007) in cattle, effective cooling systems implemented in the study herds during summer might have diminished the adverse effects of heat stress.

In conclusion, parity, RFM, and IUF were associated with the interval to resumption of ovarian activity and the incidence of multiple ovulations in postpartum dairy cows. Moreover, metritis and milk production were significant factors associated with resumption of ovarian activity, whereas presence of OC at 22 to 28 DIM 
was related to MCL on 36 to 42 DIM. Milk production and parity appeared as significant risk factors for OC. In addition, IUF, especially in the early postpartum period, was related to parity, twinning, stillbirth, RFM, and subsequent resumption of ovarian cyclicity in the studied population.

\section{ACKNOWLEDGMENTS}

This study was supported by research funds from Agrotecnio center (Lleida, Cataluna, Spain). The authors thank Reuben Mapletoft (University of Saskatchewan) for critical review of the manuscript. Our gratitude is also extended to the owners and personnel of the farms (Lleida, Spain) included in the study for allowing us access to their cows and facilities to conduct this research.

\section{REFERENCES}

Andreu-Vázquez, C., I. Garcia-Ispierto, S. Ganau, P. M. Fricke, and F. López-Gatius. 2012a. Effects of twinning on the subsequent reproductive performance and productive lifespan of high-producing dairy cows. Theriogenology 78:2061-2070.

Andreu-Vázquez, C., I. Garcia-Ispierto, and F. López-Gatius. 2012b. Photoperiod length and the estrus synchronization protocol used before AI affect the twin pregnancy rate in dairy cattle. Theriogenology 78:1209-1216.

Barlund, C. S., T. D. Carruthers, C. L. Waldner, and C. W. Palmer. 2008. A comparison of diagnostic techniques for postpartum endometritis in dairy cattle. Theriogenology 69:714-723.

Butler, W. R., R. W. Everett, and C. E. Coppock. 1981. The relationships between energy balance, milk production and ovulation in postpartum Holstein cows. J. Anim. Sci. 53:742-748.

Cady, R. A., and L. D. Van Vleck. 1978. Factors affecting twinning and effects twinning of in Holstein dairy cattle. J. Anim. Sci. 46:950-956.

Chassagne, M., J. Barnouin, and J. P. Chacornac. 1998. Predictive markers in the late gestation period for retained placenta in blackpied dairy cows under field conditions in France. Theriogenology 49:645-656.

Colazo, M. G., A. Behrouzi, D. J. Ambrose, and R. J. Mapletoft. 2015. Diameter of the ovulatory follicle at timed-AI as a predictor of pregnancy status in lactating dairy cows subjected to GnRH-based protocols. Theriogenology 84:377-383.

de Boer, M. W., S. J. LeBlanc, J. Dubuc, S. Meier, W. Heuwieser, S. Arlt, G. O. Gilbert, and S. McDougall. 2014. Invited review: Systematic review of diagnostic tests for reproductive-tract infection and inflammation in dairy cows. J. Dairy Sci. 97:3983-3999.

De Rensis, F., I. Garcia-Ispierto, and F. López-Gatius. 2015. Seasonal heat stress: Clinical implications and hormone treatments for the fertility of dairy cows. Theriogenology 84:659-666.

Detilleux, J. C., M. E. Jr Kehrli, J. R. Stabel, A. E. Freeman, and D. H. Kelley. 1995. Study of immunological dysfunction in periparturient Holstein cattle selected for high and average milk production. Vet. Immunol. Immunopathol. 44:251-267.

Dourey, A., G. C. Colazo, P. Ponce-Barajas, and D. J. Ambrose. 2011. Relationships between endometrial cytology and interval to first ovulation, and pregnancy in postpartum dairy cows in a single herd. Res. Vet. Sci. 91:e149-e153.

Dubuc, J., T. F. Duffield, K. E. Leslie, J. S. Walton, and S. J. LeBlanc. 2012. Risk factors and effects of postpartum anovulation in dairy cows. J. Dairy Sci. 95:1845-1854.

Dyck, B. L., M. G. Colazo, D. J. Ambrose, M. K. Dyck, and L. Doepel. 2011. Starch source and content in postpartum dairy cow diets: Ef- fects on plasma metabolites and reproductive processes. J. Dairy Sci. 94:4636-4646.

El-Din Zain, A., T. Nakao, M. Abdel Raouf, M. Moriyoshi, K. Kawata, and Y. Moritsu. 1995. Factors in the resumption of ovarian activity and uterine involution in postpartum dairy cows. Anim. Reprod. Sci. 38:203-214.

Faul, F., E. Erdfelder, A. G. Lang, and A. Buchner. 2007. G*Power 3: A flexible statistical power analysis program for the social, behavioral, and biomedical sciences. Behav. Res. Methods 39:175-191.

Fourichon, C., H. Seegers, and X. Malher. 2000. Effect of disease on reproduction in the dairy cow: a meta-analysis. Theriogenology 53:1729-1759.

Fricke, P. M., and M. C. Wiltbank. 1999. Effect of milk production on the incidence of double ovulation in dairy cows. Theriogenology 52:1133-1143.

Garcia-Ispierto, I., F. López-Gatius, P. Santolaria, J. L. Yániz, C. Nogareda, and M. López-Béjar. 2007. Factors affecting the fertility of high producing dairy herds in northeastern Spain. Theriogenology 67:632-638.

Garverick, H. A. 1997. Ovarian follicular cysts in dairy cows. J. Dairy Sci. 80:995-1004.

Gröhn, Y. T., and R. J. Rajala-Schultz. 2000. Epidemiology of reproductive performance in dairy cows. Anim. Reprod. Sci. 60-61:605614.

Hammon, D. S., I. M. Evjen, T. R. Dhiman, J. P. Goff, and J. L. Walters. 2006. Neutrophil function and energy status in Holstein cows with uterine health disorders. Vet. Immunol. Immunopathol. 113:21-29.

Hanzen, C. H., F. Bascon, L. Theron, and F. López-Gatius. 2007. Ovarian cyst in bovine species. 1. Definitions, symptoms and diagnosis. Annales de Medicine Veterinaire 151:247-256.

Hanzen, C. H., F. Bascon, L. Theron, and F. López-Gatius. 2008. Ovarian cysts in cattle 3 . Therapeutic. Annales de Medicine Veterinaire 152:103-115.

Hosmer, D. W., and S. Lemeshow. 1989. Applied Logistic Regression. Wiley, New York, NY.

Johnson, A. D., J. E. Legates, and L. C. Ulberg. 1966. Relationship between follicular cysts and milk production in dairy cattle. J. Dairy Sci. 49:865-868.

Kasimanickam, R., T. F. Duffield, R. A. Foster, C. J. Gartley, K. E. Leslie, J. S. Walton, and W. H. Johnson. 2004. Endometrial cytology and ultrasonography for the detection of subclinical endometritis in postpartum dairy cows. Theriogenology 62:9-23.

Kastelic, J. P., R. A. Pierson, and O. J. Ginther. 1990. Ultrasonic morphology of corpora lutea and central luteal cavities during the estrous cycle and early pregnancy in heifers. Theriogenology 34:487-498.

Kinsel, M. L., W. E. Marsh, P. L. Ruegg, and W. G. Etherington. 1998. Risk factors for twinning in dairy cows. J. Dairy Sci. 81:989-993.

Labhsetwar, A. P., W. J. Tyler, and L. E. Casida. 1963. Analysis of variation in some factors affecting multiple ovulations in Holstein cattle. J. Dairy Sci. 46:840-842.

LeBlanc, S. J. 2008. Postpartum uterine disease and dairy herd reproductive performance: A review. Vet. J. 176:102-114.

Lewis, G. S. 2004. Steroidal regulation of uterine immune defenses. Anim. Reprod. Sci. 82-83:281-294.

Lopez, H., D. Z. Caraviello, L. D. Satter, P. M. Fricke, and M. C. Wiltbank. 2005. Relationship between level of milk production and multiple ovulations in lactating dairy cows. J. Dairy Sci. 88:27832793.

López-Gatius, F. 2003. Is fertility declining in dairy cattle? A retrospective study in northeastern Spain. Theriogenology 60:89-99.

López-Gatius, F. 2012. Factors of a noninfectious nature affecting fertility after artificial insemination in lactating dairy cows. A review. Theriogenology 77:1029-1041.

López-Gatius, F., and I. Garcia-Ispierto. 2010. Ultrasound and endocrine findings that help to assess the risk of late embryo/early foetal loss by non-infectious cause in dairy cattle. Reprod. Domest. Anim. 45(Suppl. 3):15-24.

López-Gatius, F., J. Labèrnia, P. Santolaria, M. López-Béjar, and J. Rutllant. 1996. Effect of reproductive disorders previous to con- 
ception on pregnancy attrition in dairy cows. Theriogenology 46:643-648.

López-Gatius, F., M. López-Béjar, M. Fenech, and R. H. Hunter. 2005. Ovulation failure and double ovulation in dairy cattle: Risk factors and effects. Theriogenology 63:1298-1307.

López-Gatius, F., A. Mirzaei, P. Santolaria, G. Bech-Sàbat, C. Nogareda, I. García-Ispierto, Ch. Hanzen, and J. L. Yániz. 2008. Factors affecting the response to the specific treatment of several forms of clinical anestrus in high producing dairy cows. Theriogenology 69:1095-1103.

López-Gatius, F., P. Santolaria, J. Yániz, M. Fenech, and M. LópezBéjar. 2002. Risk factors for postpartum ovarian cysts and their spontaneous recovery or persistence in lactating dairy cows. Theriogenology 58:1623-1632.

López-Gatius, F., J. Yániz, and D. Madriles-Helm. 2003. Effects of body condition score change on the reproductive performance of dairy cows: A meta-analysis. Theriogenology 59:801-812.

López-Helguera, I., F. López-Gatius, and I. Garcia-Ispierto. 2012. The influence of genital tract status in postpartum period on the subsequent reproductive performance in high producing dairy cows. Theriogenology 77:1334-1342.

Lucy, M. C., J. Beck, C. R. Staples, H. H. Head, R. L. De La Sota, and W. W. Thatcher. 1992. Follicular dynamics, plasma metabolites, hormones and insulin-like growth factor I (IGF-I) in lactating cows with positive or negative energy balance during the preovulatory period. Reprod. Nutr. Dev. 32:331-341.

Mee, J. F. 1991. Factors affecting the spontaneous twinning rate and the effect of twinning on calving problems in nine Irish dairy herds. Ir. Vet. J. 44:14-20.

Morrow, D. A., S. J. Roberts, and K. McEntee. 1969. A review of postpartum ovarian activity and involution of the uterus and cervix in cattle. Cornell Vet. 59:134-154.

Nanda, A. S., W. R. Ward, and H. Dobson. 1989. The relationship between milk yield and cystic ovarian disease in cattle. Br. Vet. J. 145:39-45.

NRC. 2001. Nutrient Requirements of Dairy Cattle. 7th rev. ed. Natl. Acad. Sci., Washington, DC.

Opsomer, G., Y. T. Gröhn, J. Hertl, M. Coryn, H. Deluyker, and A. de Kruif. 2000. Risk factors for postpartum ovarian dysfunction in high producing dairy cows in Belgium: A field study. Theriogenology 53:841-857.

Ribadu, A. Y., W. R. Ward, and H. Dobson. 1994. Comparative evaluation of ovarian structures in cattle by palpation per rectum, ultrasonography and plasma progesterone concentration. Vet. Rec. 135:452-457.

Roche, J. F., D. Mackey, and M. D. Diskin. 2000. Reproductive management of postpartum cows. Anim. Reprod. Sci. 60-61:703-712.

Roth, Z., R. Meweidan, A. Shaham-Albalancy, R. Braw-Tal, and D. Wolfenson. 2001. Delayed effect of heat stress on steroid production in medium-size and preovulatory bovine follicles. Reproduction 121:745-751.

Schillo, K. K. 1992. Effects of dietary energy on control of luteinizing hormone secretion in cattle and sheep. J. Anim. Sci. 70:1271-1282.
Senosy, W. S., M. Uchiza, N. Tameoka, Y. Izaike, and T. Osawa. 2009. Association between evaluation of the reproductive tract by various diagnostic tests and restoration of ovarian cyclicity in highproducing dairy cows. Theriogenology 72:1153-1162.

Sheldon, I. M., G. S. Lewis, S. LeBlanc, and R. O. Gilbert. 2006. Defining postpartum uterine disease in cattle. Theriogenology 65:1516-1530

Sheldon, I. M., D. E. Noakes, A. N. Rycroft, D. U. Pfeiffer, and H. Dobson. 2002. Influence of uterine bacterial contamination after parturition on ovarian dominant follicle selection and follicle growth and function in cattle. Reproduction 123:837-845.

Shrestha, H. K., T. Nakao, T. Higaki, T. Suzuki, and M. Akita. 2004. Resumption of postpartum ovarian cyclicity in high-producing Holstein cows. Theriogenology 61:637-649.

Singh, J., R. D. Murray, G. Mshelia, and Z. Woldehiwet. 2008. The immune status of the bovine uterus during the peripartum period. Vet. J. 175:301-309.

Tanaka, T., M. Arai, S. Ohtani, S. Uemura, T. Kuroiwa, S. Kim, and H. Kamomae. 2008. Influence of parity on follicular dynamics and resumption of ovarian cycle in postpartum dairy cows. Anim. Reprod. Sci. 108:134-143.

Tsousis, G., R. Sharifi, and M. Hoedemaker. 2009. Associations between the clinical signs of chronic endometritis with ovarian cysts and body condition loss in German Holstein Friesian cows. J. Vet. Sci. 10:337-341.

Van Vleck, L. D., K. E. Gregory, and S. E. Echternkamp. 1991. Ovulation rate and twinning rate in cattle: heritabilities and genetic correlation. J. Anim. Sci. 69:3213-3219.

Vercouteren, M. M., J. H. Bittar, P. J. Pinedo, C. A. Risco, J. E. Santos, A. Vieira-Neto, and K. N. Galvão. 2015. Factors associated with early cyclicity in postpartum dairy cows. J. Dairy Sci. 98:229-239.

Walsh, R. B., D. F. Kelton, T. F. Duffield, K. E. Leslie, J. S. Walton, and S. J. LeBlanc. 2007. Prevalence and risk factors for postpartum anovulatory condition in dairy cows. J. Dairy Sci. 90:315-324.

Wiltbank, M., H. Lopez, R. Sartori, S. Sangsritavong, and A. Gümen. 2006. Changes in reproductive physiology of lactating dairy cows due to elevated steroid metabolism. Theriogenology 65:17-29.

Wiltbank, M. C., P. M. Fricke, S. Sangsritavong, R. Satori, and O. J. Ginther. 2000. Mechanisms that prevent and produce double ovulations in dairy cattle. J. Dairy Sci. 83:2998-3007.

Wolfenson, D., W. W. Thatcher, L. Badinga, J. D. Savio, R. Meidan, B. J. Lew, R. Braw-Tal, and A. Berman. 1995. The effect of heat stress on follicular development during the estrous cycle dairy cattle. Biol. Reprod. 52:1106-1113.

Yániz, J., F. López-Gatius, G. Bech-Sàbat, I. Garcia-Ispierto, B. Serrano, and P. Santolaria. 2008. Relationships between milk production, ovarian function and fertility in high-producing dairy herds in north-eastern Spain. Reprod. Domest. Anim. 43(Suppl. 4):38-43.

Yániz, J. L., K. Murugavel, and F. López-Gatius. 2004. Recent developments in oestrous synchronization of postpartum dairy cows with and without ovarian disorders. Reprod. Domest. Anim. 39:86-93. 